\title{
Natural Killer Group 2 Type D (NKG2D) Gene Polymorphism in Systemic Lupus Erythematosus-Suez Canal Region - Egypt
}

\author{
Hussam M. ElBahrawy', Mona S. Ghaly ${ }^{2}$, Moushira A. Mahmoud ${ }^{3}$, \\ Samir M. Abdel-Moneim³ \\ Departments of ${ }^{1}$ Biochemistry, Faculty of Science, ${ }^{2}$ Rheumatology \& Rehabilitation, and ${ }^{3}$ Medical Biochemistry, \\ Faculty of Medicine, Suez Canal University, Ismailia, Egypt
}

\begin{abstract}
Background: Natural killer group 2 type $D$ (NKG2D), an activating receptor expressed on Natural Killer (NK), is a type II transmembrane glycoprotein. Normally, the function of NK cells is the eradication of infected or distorted cells and prevention of autoimmunity. The abnormal expression of NKG2D ligands has been found to increase the susceptibility to different autoimmune disorders, including rheumatoid arthritis, multiple sclerosis and autoimmune diabetes mellitus. Aim: to assess the association of NKG2D polymorphism in Egyptian SLE patients dwelling Suez Canal region and its potential clinical correlation. Patients and Methods: NKG2D polymorphism was assessed by using polymerase chain reaction (PCR) in 50 SLE patients and 50 healthy controls and the results were analyzed using allelic discrimination software. Clinical and laboratory manifestations and disease activity using SLE disease activity index (SLEDAI) were also assessed. Results: Our results showed that the frequency of the NKG2D single nucleotide polymorphism (SNP) ( $r$ 2255336 G $\rightarrow$ A) was not significantly higher in cases of SLE compared to healthy control $(p=0.13)$. NKG2D polymorphism in SLE patients showed a statistical difference between GG genotype versus GA \& AA genotypes regarding inflammatory rash, lupus headache and hair loss. Conclusion: NKG2D single nucleotide polymorphism (SNP) seems to play no role in the susceptibility to SLE in Egyptian population of Suez Canal area.
\end{abstract}

Keywords: NKG2D, SNP, genotype, SLEDAI.

\section{Introduction}

Systemic lupus Erythematosus (SLE) is, a chronic autoimmune disease, considered to be induced by complex interactions of genetic, environmental, and hormonal factors that result in an immune dysregulation \& autoantibody production $^{(1)}$. Recent genetic association studies in the field of single nucleotide polymorphisms (SNPs) have been highly successful identified several loci associated with SLE$^{(2)}$. Moreover, viral infections may induce the disease and participate in its pathogenesis(3). Epstein-Barr virus (EBV), a $\gamma$-herpes virus responsible for infectious mononucleosis has been linked with SLE for more than 40 years (4). Elevated viral loads are found in patients with SLE with some reports indicating SLE-like disease evolving after Infectious mononu- 
cleosis caused by EBV(5). One justification for this observation is that, molecular mimicry between the EBV nuclear antigen-1 (EBNA-1) and self-ribonucleoproteins causes amplification of the humoral autoimmune response in $\mathrm{SLE}^{(6)}$. Thus, genes involved in defense mechanisms against viral infection may be considered as a risk factor for autoimmunity associated with some chronic viral infection(7). Natural killer (NK) cells, a major component of the immune system, are correlated with various autoimmune diseases such as type 1 diabetes, rheumatoid arthritis and $\operatorname{SLE}^{(8,9)}$. Typically, NK cells produce cytokines upon recognition of cells infected with virus and play an important role in conferring protective immunity against virus infection ${ }^{(10)}$. Regulation of NK cells function is governed by the fine balance between inhibitory and activating receptors ${ }^{(11)}$. Natural killer group 2 type $D\left(N K G_{2} \mathrm{D}\right)$ is an activating receptor expressed, as a homodimer, on NK and $\gamma \delta$ $T$ cells, as well as on subsets of $\mathrm{CD}_{4}+$ and CD8+ T cells ${ }^{(12)}$. NKG2D is a member of the C-type lectin-like family of transmembrane proteins and is encoded on chromosome 12 within the NK gene complex ${ }^{(13)}$. The function of NK cells in the eradication of infected, distorted, or stressed cells occurs together with tolerance to self, a property that is essential to prevent autoimmunity. However, the abnormal expression of NKG2D ligands has been associated with various autoimmune disorders, including rheumatoid arthritis, multiple sclerosis and autoimmune diabetes mellitus ${ }^{(14)}$. Recently, few reports suggested an association between NKG2D single nucleotide polymorphism (SNP) (rs2255336 G $\rightarrow$ A) and SLE ${ }^{(7)}$. This SNP results in substitution of alanine (guanine) with threonine (adenine) within the transmembrane region of NKG2D which may affect the binding of ligands ${ }^{(15)}$. However, due to the limited number of studies which was considered on Eu- ropean patients, this association needs further investigations to confirm this genetic association in other populations. We therefore studied the association of the NKG2D polymorphism in Egyptian SLE patients dwelling Suez Canal region and its potential clinical correlation.

\section{Subjects and Methods}

Subjects: Fifty female SLE patients with a mean age of $30.9 \pm 8.2$ years, fulfilling the 1997 and 2012 revised American College of Rheumatology (ACR) criteria for Systemic Lupus Erythematosus (SLE) ${ }^{(16)}$, were chosen for investigation at the Rheumatology and rehabilitation Department, Suez Canal University. The controls constituted 50 age and sex matched women with mean age 28.0 7 7.7 years. They were selected from individuals attending Suez Canal university hospital clinics for non-autoimmune diseases. The control subjects were judged to be free of SLE disease by history and clinical examination and lab investigation including liver, kidney function test, anti-nuclear antibody (ANA), Erythrocyte sedimentation rate, rheumatoid factor and $C$ reactive protein. The study was approved by the ethical committee of Suez Canal University. Informed consent was obtained from all participating subjects.

Methods: Clinical manifestations were defined as either present or absent based on the definitions in the SLE classification criteria. Disease Activity were assessed using systemic lupus erythematosus disease activity index (SLEDAI) Clinical manifestations of SLE in the patient group included central nervous system (seizure, psychosis, visual disturbances, cranial nerve disorder, lupus headache), vascular manifestations (vasculitis, Raynaud's phenomenon, thromboembolism) and musculoskeletal manifestations (myositis and arthritis). The renal manifestations encompassed urinary casts, hematuria, proteinuria and pyuria. 
Rash, alopecia and mucosal ulcers were used to assess dermal clinical findings. Hematologic findings encompassed thrombocytopenia and leucopenia, while constitutional fever is defined as fever $\left(>38^{\circ} \mathrm{C}\right)$.

Blood sampling: Five milliliters of venous blood were drawn from each subject under sterile settings and were divided as follows: $2.5 \mathrm{ml}$ were evacuated into a vacutainer tube containing EDTA anticoagulant and $2.5 \mathrm{ml}$ into a plain tube. The previous tubes were used for DNA extraction for subsequent $P C R$ amplification, and the later ones were centrifuged after complete clotting and the separated serum was used immediately for blood sugar estimation while the rest of the sera were kept in aliquots at $-20^{\circ} \mathrm{C}$ in the Oncology Diagnostic Unit, Faculty of Medicine, Suez Canal University till the end of the research.

Extraction of genomic DNA: Genomic DNA was extracted from patients' and controls' peripheral blood leucocytes of EDTA anticoagulated blood using using QIAamp DNA Blood Mini Kit (Cat \# 51104; Qiagen, UK). DNA samples concentration and purity were assessed using the NanoDrop ${ }^{\circledR}$ (ND)-1000 spectrophotometer (NanoDrop Technologies, Inc. Wilmington, USA).

Genotyping: The genotyping of the NKG2D (rs2255336) polymorphism was conducted using predesigned TaqMan 5' nuclease assay (C_22274476_10, Applied biosystems, California, USA) with allele-specific fluorogenic probes. The reaction was performed in $25 \mu \mathrm{L}$ total volume containing $40 \mathrm{ng}$ DNA in $5 \mathrm{ul}, 12.5 \mu \mathrm{L}$ TaqMan Universal Master Mix, $1.25 \mu \mathrm{L}$ of 20 $x$ SNP Genotyping Assay Mix and 6.26 ul DNAse free water. Thermal cycling was initiated with a pre-read at $60^{\circ} \mathrm{C}$ for $1 \mathrm{~min}$, hold at $50^{\circ} \mathrm{C}$ for $2 \mathrm{~min}, 95^{\circ} \mathrm{C}$ for $10 \mathrm{~min}$ followed by 40 cycles of $95^{\circ} \mathrm{C}$ for $15 \mathrm{sec}, 60^{\circ} \mathrm{C}$ for $1 \mathrm{~min}$ and post read at $60^{\circ} \mathrm{C}$ for $1 \mathrm{~min}$. $P C R$ plates were run and read in the $A B I$ StepOne Sequence Detection System (Applied Biosystems). Results were analyzed using allelic discrimination software.
Assessment of autoantibodies in serum:

ANA and anti-dsDNA antibody titers were determined by indirect immunofluorescence assay on Hep-2 cells. Anti-Smith, anti-snRNP, anti-Ro and anti-La antibody presence was determined by ELISA (Inova Diagnostics, San Diego California, USA).

\section{Statistical Analysis}

The genotype and allele frequencies were determined by direct counting. HardyWeinberg's equilibrium was evaluated using a chi-square test. Statistical comparisons between healthy control and SLE patients were performed using chi-square test, fisher exact test and two-way student's t-test. For the comparison of clinical and laboratory variables with the frequencies of polymorphic variants, we used the chi-square test to compare qualitative variables and ANOVA (or Kruskal-Wallis) for quantitative variables. A value of $\mathrm{P}<0.05$ was considered significant statistically.

\section{Results}

We investigated $\mathrm{NKG}_{2} \mathrm{D}$ single nucleotide polymorphism in 50 SLE patients, and 50 healthy controls. Demographic characteristics of SLE patients and control are Summarized in table1, showing no difference between the two groups concerning age and sex. The clinical characteristics of SLE patients are represented in table 2 . Table (3) describes the Disease activity index where high disease activity subgroup was the most common among patients (40\%). Analysis of the NKG2D gene polymorphism did not show a significant deviation from Hardy-Weinberg equilibrium in patients and controls. Table (4) shows Alleles frequencies and distribution of NKG2D SNP (rs $2255336 \mathrm{G} \rightarrow \mathrm{A}$ ) Genotypes in SLE patients and their controls. Comparison between different genotypes indicated that there was no statistical difference reported between both studied groups, $\mathrm{p}$ - 
value (>0.05). Our finding showed that there was no statistically difference in all laboratory characteristics (ANA, Anti-ds DNA Ab, Anti-Ro, Anti-La, C3, C4, Thrombocytopenia, and Leukopenia) in SLE group, $G G$ versus $G A$ \& AA. On the other hand, dis- tribution of clinical characteristics according to NKG2D polymorphism in SLE patients showed statistical difference between $G G$ versus GA \& AA in Inflammatory rash, lupus headache, Hair loss (table 5).

Table 1: Demographic characteristics of SLE, and control groups

\begin{tabular}{|l|c|c|}
\hline Characteristic & SLE & Control \\
\hline Female gender@ & $47(94 \%)$ & $50(100 \%)$ \\
\hline Age (Years) ${ }^{\&}$ & $30.9 \pm 8.2$ & $28.0 \pm 7.7$ \\
\hline Disease Duration (Months) $^{\&}$ & $4.88 \pm 4.93$ & - \\
\hline SLEDAI $^{\&}$ & $19.7 \pm 12.9$ & - \\
\hline Positive ANA@ & $100(100 \%)$ & $3(3 \%)$ \\
\hline Positive Anti-ds DNA@ & $16(32 \%)$ & 0 \\
\hline Positive Anti-Ro@ & $4(16 \%)$ & 0 \\
\hline Positive Anti-La@ & $6(12 \%)$ & $1(2 \%)$ \\
\hline Positive Anti-SNRP@ & $2(4 \%)$ & 0 \\
\hline Hypocomplementemia@ & $17(34 \%)$ & $2(4 \%)$ \\
C3 & $14(34 \%)$ & $3(6 \%)$ \\
C4 &
\end{tabular}

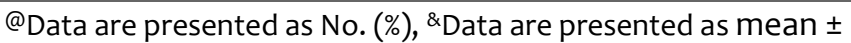
SD, SLEDAI: Systemic Lupus erythematosus disease activity index, ANA: antinuclear antibody, Anti-ds DNA Ab: anti double strand DNA antibody, Anti-Ro, Anti-la: antinuclear autoantibodies, C3, C4: Complement system proteins

\section{Discussion}

Systemic lupus Erythematosus (SLE) is a prototypic autoimmune disease characterized by the production of antibodies against cell nucleus components associated with diverse arrays of clinical manifestations. It is caused by complex interactions between genetic risk, environmental and hormonal factors that result in an immune dysregulation and autoantibody production $^{(1,17)}$. Multiple studies have indicated that SLE incidence exhibits a strong genetic background. NKG2D, an activating NK receptor, plays a major role in viral and tumor defense. Formerly, two reports suggested an association between NKG2D single nucleotide polymorphism (SNP) $($ rs2255336 $\mathrm{G} \rightarrow \mathrm{A}$ ) and SLE but not among $\operatorname{Egyptians}^{(7,15)}$. So, we devoted our work to study possible association of an SNP in the transmembrane region of NKG2D gene variant with SLE in Ismailia region- Egypt. We have found that the frequency of the NKG2D single nucleotide polymorphism $(\mathrm{SNP})$ ( $\mathrm{rs} 2255336 \mathrm{G} \rightarrow \mathrm{A}$ ) was not significantly higher in cases of SLE compared to healthy control $(p=0.13)$. These results were similar to the work of Kabalak et al., (2010) regarding a Spanish cohort (66.2\% vs $62.2 \%$ controls; $p=0.054$ ) but inconsistent with their results in the same research regarding the German cohort (70.4\% vs $60.8 \%$ controls; $p=0.0027)^{(7)}$. In addition, our results were inconsistent with Piotrowski et al. (2012), who studied the frequency of (NKG2D) receptor Thr72Ala (rs2255336) polymorphism in patients with SLE and controls in a sample of Polish population. The frequency of the NKG2D Thr allele in 
patients and controls was respectively, 15 and $21 \%,(p=0.0046)$. They concluded a protective effect of the NKG2D 72Thr gene $(G / G)$ variant from the incidence of SLE ${ }^{(15)}$.

Table 2: clinical characteristics of SLE patients

\begin{tabular}{|l|c|}
\hline Organ involvement/ active & $\mathrm{n}(\%)$ \\
\hline Seizures & $3(6 \%)$ \\
\hline psychotic features & $4(8 \%)$ \\
\hline Impaired intellectual function & $2(4 \%)$ \\
\hline visual disturbance & $7(14 \%)$ \\
\hline sensory or motor neuropathy & $6(12 \%)$ \\
\hline Headache & $12(24 \%)$ \\
\hline CVA & $3(6 \%)$ \\
\hline Vasculitis & $4(8 \%)$ \\
\hline Arthritis & $29(58 \%)$ \\
\hline Number of joints affected: & $6 / 29$ \\
$1-2$ joints & $17 / 29$ \\
\hline $3-4$ joints & $6 / 29$ \\
\hline M joints & $5(10 \%)$ \\
\hline Muscle affection & $21(42 \%)$ \\
\hline Inflammatory rash & $33(66 \%)$ \\
\hline hair loss & $28(56 \%)$ \\
\hline mouth ulcer & $10(10 \%)$ \\
\hline Proteinuria & $12(24 \%)$ \\
\hline Thrombocytopenia & $0(0 \%)$ \\
\hline Hemolytic anemia & $11(22 \%)$ \\
\hline Leucopenia & $18(36 \%)$ \\
\hline Protein in urine & $17(34 \%)$ \\
\hline Casts in urine & $16(32 \%)$ \\
\hline RBCs in urine & $21(42 \%)$ \\
\hline WBCs in Urine & $4(8 \%)$ \\
\hline$\uparrow$ CPK/ aldose [n (\%)] & \\
\hline & \\
\hline
\end{tabular}

A lack of consistent results from different studies and population groups tends to create an ambiguity about the role of genetic variations in the pathogenesis of SLE. A likely reason is that many of the individ ual genetic variations have only a modest effect on the risk of SLE but their effects are enhanced in synergism with other genetic and environmental factors. Moreover, the dissimilarities among population groups, including differences in age, sex, ethnicity, and variances in clinical end points can significantly influence the results of genetic association studies ${ }^{(1,17)}$.

Table 3: SLEDAI score among SLE patients

\begin{tabular}{|l|c|}
\hline Disease activity Score & $\mathrm{n}(\%)$ \\
\hline Mild & $14(28 \%)$ \\
\hline Moderate & $16(32 \%)$ \\
\hline High & $20(40 \%)$ \\
\hline
\end{tabular}

Furthermore, we studied distribution of clinical characteristics according to NKG2D genotypes in SLE patients, and we have found significant statistical difference between both studied groups GG versus GA \& AA regarding inflammatory rash and hair loss. Inflammatory rash was higher among GA \& AA genotypes (62\%) in comparison to GG genotype (38\%) and there was a statistical difference $(p=0.03)$. Also, hair loss was higher among $G A$ \& AA genotypes (54\%) compared to GG genotype (45\%) $(p=0.036)$. These findings were inconsistent with the work of Piotrowski and colleagues, in which they didn't find any significant association between the NKG2D Thr72Ala polymorphism with SLE clinical manifestations and the presence of autoantibodies except for the presence of antidsDNA $A b^{(15)}$.

Table 4: Alleles frequencies, and genotypes distribution of NKG2D -gene polymorphisms in control and SLE patients

\begin{tabular}{|c|c|c|c|c|c|c|c|}
\hline NKG2D -gene & \multicolumn{2}{|c|}{$\begin{array}{c}\text { Control } \\
\mathrm{N} \%\end{array}$} & \multicolumn{2}{|c|}{$\begin{array}{l}\text { SLE } \\
\mathrm{N} \%\end{array}$} & $P$ & OR & $95 \% \mathrm{Cl}$ \\
\hline G allele & 82 & 82 & 73 & 73 & \multirow{2}{*}{$0.13^{a}$} & \multirow{2}{*}{1.16} & \multirow{2}{*}{$0.715-2.18$} \\
\hline A allele & 18 & 18 & 27 & 27 & & & \\
\hline GG & 34 & 68 & 28 & 56 & $0.303^{a}$ & 1.67 & $0.74-3.77$ \\
\hline$G A$ & 14 & 28 & 17 & 34 & $0.665^{a}$ & 0.75 & $0.32-1.77$ \\
\hline AA & 2 & 4 & 5 & 10 & $0.436^{b}$ & 0.38 & $0.07-2.03$ \\
\hline${ }^{\#} \mathrm{CA}+\mathrm{AA}$ & 16 & 32 & 22 & 44 & \multicolumn{3}{|c|}{0.199} \\
\hline
\end{tabular}

${ }^{\mathrm{a}}=$ Chi-square test; ${ }^{\mathrm{b}}=$ Fisher's exact test; $(\mathrm{Cl})=$ confidence interval; $\mathrm{OR}=$ Odds ratio.

${ }^{*}=p<0.05$ is statistically significant. ${ }^{*}=G A+A A$ vs. GG. 


\section{Conclusion}

our study did not provide evidence of significant association between NKG2D $($ rs2255336 G $\rightarrow$ A) SNP and SLE, signifying that this polymorphism seems to play no role in the susceptibility to SLE in our Egyptian population in Suez Canal area.

\section{References}

1. Edberg JC, Wu J, Langefeld CD. Genetic variation in the CRP promoter: association with systemic lupus erythematosus. Human Molecular Genetics. 2008;17(8):1147-1155.
2. Gregersen PK, Olsson LM. Recent advances in the genetics of autoimmune disease. Annual Review of Immunology. 2009; 27:363-391

3. McClain MT, Poole BD, Bruner BF, Kaufman KM, Harley JB, James JA. An altered immune response to EpsteinBarr nuclear antigen 1 in pediatric systemic lupus erythematosus. Arthritis Rheum 2006; 54:3608.

4. Young LS, Rickinson AB. Epstein-Barr virus: 40 years on. Nat Rev Cancer. 2004;4(10):757-768.

5. Gross AJ, Hochberg D, Rand WM, Thorley-Lawson DA. EBV and systemic lupus erythematosus: a new perspective. J Immunol. 2005;174(11):6599-6607.

Table 5. Distribution of clinical characteristics according to NKG2D polymorphism in SLE patients $(\mathrm{N}=50)$

\begin{tabular}{|c|c|c|c|c|c|}
\hline & & \multirow[t]{2}{*}{ value } \\
\hline & No. & $\%$ & No. & $\%$ & \\
\hline Arthritis & 16 & $55.2 \%$ & 13 & $44.8 \%$ & 0.890 \\
\hline \multirow{5}{*}{$\begin{array}{l}\text { Skin involvement } \\
\text { - Inflammatory rash } \\
\text { - Hair loss } \\
\text { - Senor/motor neuropathy } \\
\text { - Ulcerations/ gangrene } \\
\text { - Splinter hemorrhage }\end{array}$} & 8 & $38.1 \%$ & 13 & $61.9 \%$ & $0.03 *$ \\
\hline & 15 & $45.5 \%$ & 18 & $54.5 \%$ & $0.036 *$ \\
\hline & 4 & $66.7 \%$ & 2 & $33.3 \%$ & $0.683^{a}$ \\
\hline & 2 & $66.7 \%$ & 1 & $33.3 \%$ & $1.00^{a}$ \\
\hline & 2 & $50 \%$ & 2 & $50 \%$ & $1.00^{a}$ \\
\hline \multirow{5}{*}{$\begin{array}{ll}\text { CNS involvement } \\
\text { - } \\
\text { - } & \text { Leipus headache } \\
\text { - } & \text { Psychotic features } \\
\text { - } & \text { Intellectual function } \\
\text { - } & \text { Visual disturbances } \\
\end{array}$} & 3 & $25 \%$ & 9 & $75 \%$ & 0.053 \\
\hline & 1 & $33.3 \%$ & 2 & $66.7 \%$ & $0.576^{a}$ \\
\hline & 2 & $50 \%$ & 2 & $50 \%$ & $1.00^{\mathrm{a}}$ \\
\hline & 0 & $0 \%$ & 2 & $100 \%$ & $0.103^{a}$ \\
\hline & 4 & $57.1 \%$ & 3 & $42.9 \%$ & $1.00^{a}$ \\
\hline Fever & 4 & $44.4 \%$ & 5 & $55.6 \%$ & $0.481^{a}$ \\
\hline Mouth ulcer & 16 & $57.1 \%$ & 12 & $42.9 \%$ & 0.854 \\
\hline Pleural affection & 8 & $53.3 \%$ & 7 & $46.7 \%$ & 0.804 \\
\hline CVA & 2 & $66.7 \%$ & 1 & $33.3 \%$ & $1.00^{a}$ \\
\hline Vasculitis & 3 & $75 \%$ & 1 & $25 \%$ & $0.621^{a}$ \\
\hline Muscle affection & 3 & $60 \%$ & 2 & $40 \%$ & $1.00^{a}$ \\
\hline
\end{tabular}

6. McClain MT, Heinlen LD, Dennis GJ, Roebuck J, Harley JB, James JA. Early events in lupus humoral autoimmunity suggest initiation through molecular mimicry. Nat Med. 2005;11(1):85-89.

7. Kabalak G, Thomas RM, Martin J. Association of NKG2D gene variant with systemic lupus erythematosus in two populations. Hum Immunol.2010; 71(1):748.
8. Pisetsky DS, Rönnblom L. Systemic lupus erythematosus: a matter of life and death. Arthritis Rheum. 2009; 60, 1567-1570.

9. Popko K, Górska E. The role of natural killer cells in pathogenesis of autoimmune diseases. Eur J Immunol. 2015; 40(4):470-476. 
10. Moretta L, Bottino C, Pende D, Mingari MC, Biassoni R, Moretta A. Human natural killer cells: their origin, receptors and function. Eur J Immunol 2002; 32:1205-11.

11. Lanier LL. NK cell recognition. Annu. Rev. Immunol 2005: 23: 225-274.

12. Upshaw JL, Arneson LN, Schoon RA, Dick $C J$, Billadeau DD, Leibson PJ. $N K G_{2} D$ mediated signaling requires a DAP10-bound Grb2-Vav1 intermediate andphosphatidylinositol-3-kinase in human natural killer cells. Nat Immunol 2006; 7:524-32.

13. Eagle RA, Trowsdale J. Promiscuity and the single receptor: NKG2D.Nat. Rev. Immunol 2007;7: 737-744.

14. Caillat-Zucman. How NKG2D ligands trigger autoimmunity? Hum immunol 2007; 67(3):204-7.
15. Piotrowski $P$, Lianeri $M$, Olesinska $M$, Jagodzinski PP. Prevalence of the NKG2D Thr72Ala polymorphism in patients with systemic lupus erythematosus. Mol Biol Rep. 2012; 39(2):1343-7.

16. Petri $M$, Orbai AM, Alarco ' $n$ GS, et al. Derivation and validation of the Systemic Lupus International Collaborating Clinics classification criteria for systemic lupus erythematosus. Arthritis Rheum2012; 64: 2677-2686.

17. Kyttaris VC, Krishnan S, Tsokos GC. Systems biology in systemic lupus erythematosus: integrating genes, biology and immune function. Autoimmunity. 2006;39(8):705-709. 
